\title{
Possible mechanism for acceleration of meiotic progression of bovine follicular oocytes by growth factors in vitro
}

\author{
M. Sakaguchi ${ }^{1}$, T. Dominko² ${ }^{2}$ N. Yamauchi ${ }^{3}$, \\ M. L. Leibfried-Rutledge ${ }^{2}$, T. Nagai ${ }^{3}$ and N. L. First ${ }^{2}$ \\ ${ }^{1}$ National Agricultural Research Center for Hokkaido Region, Department of Animal \\ Production, Sapporo, Hokkaido 062-8555, Japan; ${ }^{2}$ University of Wisconsin, Department of \\ Animal Sciences, Madison, WI 53706, USA; and ${ }^{3}$ National Institute of Agrobiological \\ Sciences, Developmental Biology Department, Tsukuba, Ibaraki 305-8602, Japan
}

The mechanism for the accelerating effects of epidermal growth factor (EGF) and insulin-like growth factor I (IGF-I) on the meiotic cell cycle of bovine oocytes cultured in vitro was investigated. Cumulus-oocyte complexes (COCs) were obtained from small ( $\leqslant 3 \mathrm{~mm}$ in diameter), medium $(4-6 \mathrm{~mm}$ in diameter) or large $(7-10 \mathrm{~mm}$ in diameter) ovarian follicles and cultured with or without a combination of EGF and IGF-I (growth factors). Growth factors significantly increased the frequency of first polar body extrusion of oocytes derived from small follicles at 16 h of culture (PB16 oocytes; with growth factors: $75 \%$; without growth factors: $55 \%$ ), but did not increase the frequency in oocytes from medium or large follicles. COCs from small follicles were cultured with individual growth factors and sampled for kinase activity. The frequencies of polar body extrusion in EGF only $(67 \%)$ and EGF + IGF-I
$(75 \%)$ treatment groups were significantly higher than those in the control (no growth factor) group (49\%), but not significantly higher than in the IGF-I only group $(63 \%)$. The $\mathbf{H 1}$ kinase activity at $6-8 \mathrm{~h}$ of culture in each group increased significantly from the baseline value at $0 \mathrm{~h}$ of culture, and the $\mathrm{H} 1$ kinase activities in the EGF only, IGF-I only and EGF + IGF-I treatment groups were significantly higher than those in the control group at $8 \mathrm{~h}$ of culture. MAP kinase activity was significantly higher than the baseline value and significantly higher than that in the control group at $6 \mathrm{~h}$ of culture in the EGF treatment group only. In conclusion, EGF and IGF-I act on COCs from small follicles to accelerate the meiotic cell cycle of the oocytes. This accelerating effect may be related to increased H1 and MAP kinase activities during the early stages of maturation.

\section{Introduction}

During ovarian follicular development, several growth factors and cytokines act as intra-ovarian regulators in vivo (Greenwald and Roy, 1994), and at the follicle the action of gonadotrophins is modulated by locally produced paracrine and autocrine growth factors (Bevers et al., 1997). Sakaguchi et al. (2000) reported that the progression of meiosis in bovine oocytes enclosed with cumulus cells was accelerated by exposure of the oocytes to growth factors (epidermal growth factor (EGF) and insulin-like growth factor I (IGF-I)) in serumfree maturation medium, but that their subsequent developmental competence was not improved. Treatment with EGF during maturation culture decreased the time required for germinal vesicle breakdown (GVBD) of denuded oocytes in mice (Das et al., 1991) and EGF has a maturationpromoting effect on denuded bovine oocytes (Lonergan et al., 1996). However, it has also been reported that growth factors do not enhance or accelerate the progress of meiosis of denuded bovine oocytes in vitro (Lorenzo et al., 1994; Sakaguchi et al., 2000). Therefore, it appears likely that in

Email: saka99@affrc.go.jp bovine oocytes under the experimental conditions used by Sakaguchi et al. (2000), the enclosing cumulus cells mediate the effects of growth factors on the progress of maturation.

Bovine oocytes recovered from follicles other than preovulatory follicles have yet to undergo certain prematurational events (Barnes et al., 1993; Hyttel et al., 1993). There have been many reports showing that oocytes derived from small follicles have low maturational and developmental competence in vitro (Tan and Lu, 1990; Pavlok et al., 1992; Barnes et al., 1993; Lonergan et al., 1994; Kubota and Yang, 1998). In addition, the concentrations of growth factors in follicular fluid (Hsu et al., 1987; Westergaard et al., 1990; Spicer and Geisert, 1992) and of their receptors in ovarian granulosa cells (Spicer et al., 1994) are dependent on follicular size. Elucidation of the mechanism by which growth factors stimulate the resumption of meiosis will lead to better understanding of the control of meiotic maturation in mammalian oocytes.

In mammalian oocytes, meiotic maturation under in vitro conditions is affected by many intrinsic and extrinsic factors. As the maturation/M-phase promoting factor (MPF) has been identified as a key regulator of both meiotic and mitotic cell cycles (Masui and Markert, 1971; Lohka et al., 
1988), the role of MPF in driving the meiotic resumption of bovine oocyte maturation has been investigated (Campbell et al., 1993; Wu et al., 1997). MPF activity can be determined by measuring its kinase activity using exogenous histone $\mathrm{H} 1$ as a substrate (Nurse, 1990). In addition, other kinases are activated before or concurrently with MPF during initiation of meiosis in mammalian oocytes (Sirard et al., 1998). One important group of these kinases is the mitogen-activated protein (MAP) kinases (Sun et al., 1999), which are also called extracellular regulated protein kinases (ERKs) because they are regulated by a wide variety of extracellular signals (Mordret, 1993). Motlik et al. (1998) reported that, in cattle oocytes, p42-ERK2 and p44-ERK1 are phosphorylated at GVBD and remain phosphorylated until metaphase II. MAP kinase activity can also be determined by measuring its activity using exogenous myelin basic protein (MBP) as a substrate (Kalab et al., 1996; Motlik et al., 1998).

The aim of the present study was to investigate the mechanism of acceleration triggered by growth factors of meiotic progression of bovine follicular oocytes. Firstly, meiotic acceleration of oocytes in response to stimulation by growth factors (EGF and IGF-I) was observed using bovine cumulus-oocyte complexes (COCs) from follicles of different diameters. The results of this initial experiment indicated that only COCs from small follicles responded to the stimulation. Hence, the acceleration effects of individual growth factors on COCs derived from small follicles were examined and the effects of these growth factors on the kinetics of the cell cycleregulating kinase activities of oocytes during early maturation were investigated.

\section{Materials and Methods}

\section{Collection of follicular oocytes}

Bovine ovaries (mainly from Holstein cows) were obtained from an abattoir and transported to the laboratory in physiological saline $(0.9 \%(\mathrm{w} / \mathrm{v}) \mathrm{NaCl})$ in an insulated container within 3-6 h of recovery. The temperature of the container upon arrival was approximately $30^{\circ} \mathrm{C}$. COCs were aspirated from peripheral antral follicles, which were grouped into three categories (small: $\leqslant 3 \mathrm{~mm}$ in diameter; medium: 4-6 $\mathrm{mm}$ in diameter; large: $7-10 \mathrm{~mm}$ in diameter), using a suction pump under low vacuum with an 18-gauge needle. Only evenly granulated oocytes with a compact cumulus investment were used. The COCs were washed four times with a Hepes-buffered Tyrode's medium supplemented with $0.2 \mathrm{mmol}$ pyruvate $\mathrm{I}^{-1}$ and $0.3 \%(\mathrm{w} / \mathrm{v})$ polyvinylpyrrolidone (TALP; Bavister et al., 1983). All of the media used in this study were supplemented with $25 \mu \mathrm{g}$ gentamycin sulphate $\mathrm{ml}^{-1}$. The processing time from aspiration to culture was $<2 \mathrm{~h}$. All chemicals were purchased from Sigma Chemical Company (St Louis, MO), unless stated otherwise.

\section{In vitro maturation (IVM)}

The basic medium for IVM was tissue culture medium 199 with Earle's salts (TCM199; Van Water Rogers,
Chicago, IL) supplemented with $0.2 \mathrm{mmol}$ sodium pyruvate $\mathrm{I}^{-1}$. Bovine COCs (7-10) were cultured in a $50 \mu \mathrm{l}$ droplet of medium, with supplements as described below, under $10 \mathrm{ml}$ paraffin oil in $60 \mathrm{~mm}$ Petri dishes at $39^{\circ} \mathrm{C}$ under $5 \% \mathrm{CO}_{2}$ in air with saturated humidity. The growth factors used in this study were recombinant human EGF and recombinant human IGF-I, both of which were used at a concentration of $10 \mathrm{ng} \mathrm{ml}^{-1}$. Growth factors were reconstituted in TCM199 containing $1 \mathrm{mg}$ bovine serum albumin fraction $\mathrm{V}$ (BSA) $\mathrm{ml}^{-1}$, and were stored at $-20^{\circ} \mathrm{C}$ until required. The final concentration of BSA in the maturation droplet of each treatment was $<0.004 \%(\mathrm{w} / \mathrm{v})$.

\section{Timing of polar body extrusion of oocytes from follicles of different sizes}

In the first experiment, COCs were cultured with or without growth factors (EGF and IGF-I). For observation of completion of meiosis I, the oocytes were treated with hyaluronidase $\left(2 \mathrm{mg} \mathrm{m}^{-1}\right.$ in TALP) for a few minutes and stripped free of cumulus cells by repeated pipetting through a small bore pipette. Examination for polar body extrusion was performed at $16 \mathrm{~h}$ after the onset of maturation. All denuded oocytes were examined for the presence of a polar body under a stereomicroscope (Dominko and First, 1997). Oocytes that extruded the first polar body within $16 \mathrm{~h}$ (PB16 oocytes) after the onset of maturation were mounted on a glass slide and fixed overnight in acetic acid-ethanol (1:3) to determine the cell cycle stage. After staining with $1 \%$ $(\mathrm{w} / \mathrm{v})$ orcein in $40 \%(\mathrm{w} / \mathrm{v})$ acetic acid, the chromatin configuration of the oocytes that extruded the first polar body within $16 \mathrm{~h}$ was visualized under phase-contrast microscopy. The remaining oocytes were allowed to mature for a further $8 \mathrm{~h}$ and examined again for the presence of a polar body (PB24 oocytes).

\section{Determination of histone $\mathrm{H} 1$ kinase and MAP kinase activities}

In the second experiment, COCs from small follicles were assigned to four different maturation treatments: (i) no growth factors; (ii) EGF only; (iii) IGF-I only; and (iv) both EGF and IGF-I. In each treatment group, oocytes for measurement of kinase activities were sampled randomly at 0, 4, 6 and $8 \mathrm{~h}$ after initiation of maturation culture. At each time point, five COCs were stripped free of cumulus cells by repeated pipetting, and denuded oocytes were snap frozen in liquid nitrogen and stored at $-70^{\circ} \mathrm{C}$ until use. The remaining COCs were examined for polar body extrusion, as described above. Five PB16 oocytes in each treatment group were also sampled for kinase assay and the remaining PB16 oocytes were fixed and stained for determination of cell cycle stage, as described above.

Kinase assay was performed according to Dominko and First (1996). The reaction mixture contained $5 \mu \mathrm{l}$ sample, $1 \mu \mathrm{l}$ histone $\mathrm{H} 1 \quad\left(1.0 \mathrm{mg} \mathrm{ml}^{-1}\right), 1 \mu \mathrm{l}$ myelin basic protein

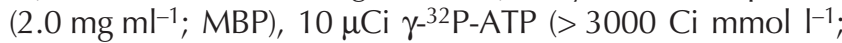
Amersham, Arlington Heights, IL) and $5 \mu \mathrm{l}$ kinase buffer 
Table 1. Polar body extrusion of bovine oocytes derived from follicles of different diameters cultured with or without growth factors

\begin{tabular}{|c|c|c|c|c|}
\hline \multirow{2}{*}{$\begin{array}{l}\text { Polar body } \\
\text { extrusion }\end{array}$} & \multirow[b]{2}{*}{ Growth factors } & \multicolumn{3}{|c|}{ Follicular size (diameter)* } \\
\hline & & Small $(\leqslant 3 \mathrm{~mm})$ & Medium (4-6 mm) & Large $(7-10 \mathrm{~mm})$ \\
\hline \multirow[t]{2}{*}{ PB16 } & - & $108(55 \pm 5)$ & $105(63 \pm 6)$ & $40(62 \pm 5)$ \\
\hline & + & $147(75 \pm 2)^{\mathrm{a}}$ & $99(71 \pm 7)$ & $43(61 \pm 8)$ \\
\hline \multirow[t]{2}{*}{ PB24 } & - & $59(32 \pm 3)$ & $43(26 \pm 5)$ & $16(22 \pm 5)$ \\
\hline & + & $32(17 \pm 2)^{\mathrm{a}}$ & $35(24 \pm 6)$ & $22(30 \pm 9)$ \\
\hline \multirow[t]{2}{*}{ No polar body } & - & $23(13 \pm 3)$ & $16(11 \pm 3)$ & $11(16 \pm 4)$ \\
\hline & + & $15(8 \pm 0)$ & $8(6 \pm 2)$ & $7(9 \pm 1)$ \\
\hline \multirow[t]{2}{*}{ Total } & - & 190 & 164 & 67 \\
\hline & + & 194 & 142 & 72 \\
\hline
\end{tabular}

*Values are number of oocytes (mean $\% \pm$ SE of five replicate experiments).

PB16 and PB24: oocytes that have extruded the first polar body by 16 or $24 \mathrm{~h}$ after the initiation of culture, respectively.

No polar body: oocytes that have not extruded their first polar body by $24 \mathrm{~h}$ after initiation of culture.

Growth factors: cultured with (+) or without (-) epidermal growth factor (EGF) and insulin-like growth factor I (IGF-I) in the maturation medium with $0.3 \%(\mathrm{w} / \mathrm{v})$ polyvinylpyrrolidone.

aSignificantly different from corresponding value without growth factors in culture medium $(P<0.05)$.

(80 mmol $\beta$-glycerophosphate $\mathrm{I}^{-1}, 20 \mathrm{mmol}$ ethylene glycolbis ( $\beta$-aminoethyl ether), $N, N, N^{\prime}, N^{\prime}$-tetraacetic acid $I^{-1}$, $15 \mathrm{mmol} \mathrm{MgCl}_{2} \mathrm{I}^{-1}$ and $1 \mathrm{mmol}$ dithiothreitol $\mathrm{I}^{-1}$ ) with inhibitors ( 1 mmol sodium ortho-vanadate $\mathrm{I}^{-1}, 10 \mu \mathrm{g}$ aprotinin $\mathrm{ml}^{-1}$ and $10 \mu \mathrm{g}$ pepstatin $\mathrm{A} \mathrm{ml}^{-1}$ ). The mixture was incubated for $30 \mathrm{~min}$ at room temperature and the reaction was stopped by the addition of $10 \mu \mathrm{l}$ of $2 \times$ concentrated electrophoresis sample buffer containing $100 \mathrm{mmol}$ dithiothreitol $\mathrm{I}^{-1}$. The reactions were subjected to electrophoresis on $12.5 \%(\mathrm{w} / \mathrm{v})$ SDS polyacrylamide gels, and phosphorylated histone and MBP bands were visualized by autoradiography. The intensity of the bands was analysed by imaging densitometry (Model GS-700; Bio-Rad, Hercules, CA).

\section{Statistical analysis}

The observations on polar body extrusion and cell cycle stage were recorded as percentages and transformed by arcsine transformation to normalize the variance before analysis. The transformed data and densitometric value of the kinase activities were analysed by ANOVA using the GLM procedure (SAS, 1989). The transformed means of frequency of polar body extrusion and cell cycle stage in oocytes derived from follicles of specific sizes were compared by non-paired $t$ test to evaluate the accelerating effects of EGF and IGF-I. The mean values of kinase activity as indicated by densitometric value at each time point were compared with the mean values at $0 \mathrm{~h}$ (before onset of maturation culture) by paired $t$ test. All other means were compared by Fisher's least significant difference test. $P<0.05$ was considered significant.

\section{Results}

Effects of follicular size on response to growth factors

A total of 829 COCs (139 from large follicles, 306 from medium follicles and 384 from small follicles) was examined in five replicates. Two-way ANOVA (follicular size and supplementation with growth factors) indicated that there were no main effects or interaction effects on the timing of polar body extrusion. However, for oocytes derived from small follicles, the frequency of PB16 oocytes in the growth factor $(+)$ group was significantly higher than that in the growth factor $(-)$ group, and the frequency of PB24 oocytes in the growth factor $(+)$ group was significantly lower than that in the growth factor (-) group (Table 1). Observation of the chromatin configuration of PB16 oocytes indicated that $31-46 \%$ were in metaphase II, $52-62 \%$ were in anaphase I or telophase I of the meiotic cell cycle, and $<8 \%$ were in other stages or had degenerated (Fig. 1). There were no significant differences in the frequencies of cell cycle stages of PB16 oocytes collected from follicles of different sizes matured with or without growth factors.

\section{Response of oocytes derived from small follicles to individual growth factors}

COCs $(n=1118)$ from small follicles were prepared for treatment with individual growth factors and sampled for kinase assay. The timing of polar body extrusion of 818 oocytes in response to individual growth factors was examined in five replicate experiments. The frequencies of 


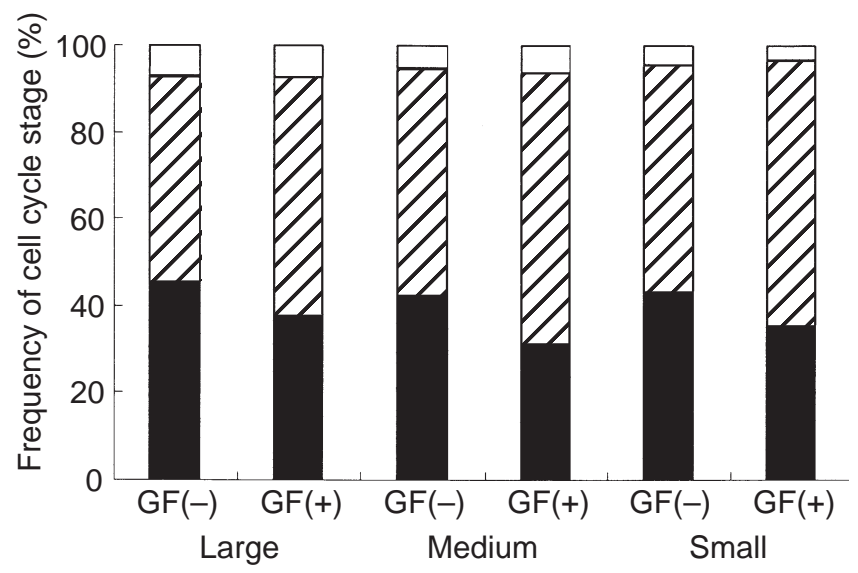

Fig. 1. Cell cycle stage of bovine oocytes that have an extruded polar body within $16 \mathrm{~h}$ of the start of culture (PB16). $\mathbf{\square}$ : Metaphase II; $Z$ : anaphase I or telophase I oocytes; $\square$ : unmatured oocytes. These oocytes with cumulus cells were derived from large (7-10 $\mathrm{mm})$, medium $(4-6 \mathrm{~mm})$ or small $(\leqslant 3 \mathrm{~mm})$ follicles and treated with (+) or without (-) growth factors (GF; epidermal growth factor and insulin-like growth factor I) during maturation culture. Data presented are means of five replicate experiments. No significant differences were detected.

polar body extrusion of oocytes from small follicles treated with individual growth factors are shown (Table 2). EGF supplementation (EGF only and EGF + IGF-I) increased the frequencies of PB16 oocytes significantly and decreased the frequencies of PB24 oocytes compared with the control frequencies. IGF-I treatment also caused an increased frequency of PB16 oocytes and a decreased frequency of PB24 oocytes, although the differences from the control treatment were not significant. The frequency of oocytes without a polar body at $24 \mathrm{~h}$ in the EGF + IGF-I group was significantly lower than in the control and EGF only groups. Observation of the chromatin configuration of oocytes indicated that there were no significant differences in the frequencies of cell cycle stages of PB16 oocytes collected from small follicles and cultured with individual growth factors (Fig. 2).

\section{Kinase activities in oocytes derived from small follicles and treated with growth factors}

Determination of kinase activity was performed three times (total 300 oocytes). H1 kinase activity in each group of oocytes was increased significantly at $6-8 \mathrm{~h}$ of culture compared with the value at $0 \mathrm{~h}$ of culture, and the values in the EGF only, IGF-I only and EGF + IGF-I treatment groups at $8 \mathrm{~h}$ of culture were significantly higher than that in the control group (Fig. 3a). In the PB16 oocytes, the H1 kinase activity in each group of oocytes was decreased.

MAP kinase activity of oocytes in the EGF only group at $6 \mathrm{~h}$ of culture was significantly higher than activity at $0 \mathrm{~h}$ of culture. MAP kinase activity was also significantly higher in the EGF only group than in the control and EGF + IGF-I

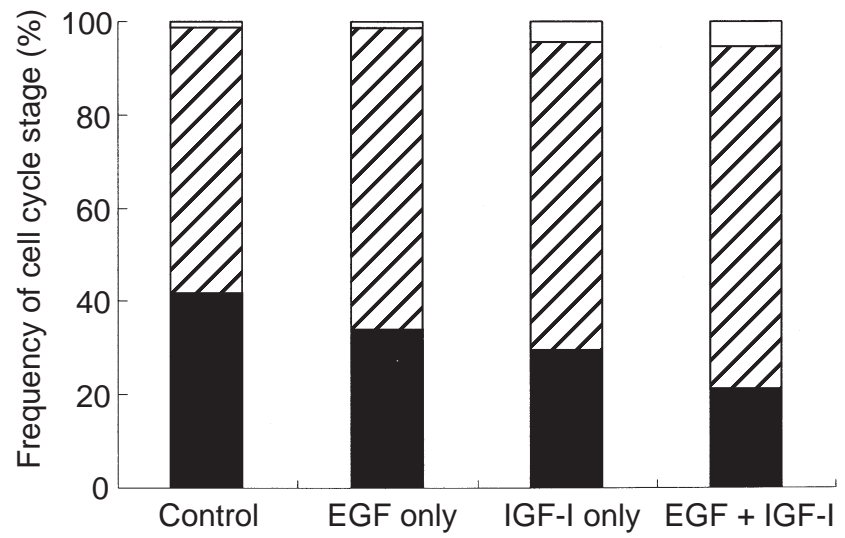

Fig. 2. Cell cycle stage of bovine oocytes that have an extruded polar body within $16 \mathrm{~h}$ of the start of culture (PB16). $\mathbf{a}$ : Metaphase II; $\square$ : anaphase I or telophase I oocytes; $\square$ : unmatured oocytes. These oocytes with cumulus cells were derived from small $(\leqslant 3$ $\mathrm{mm}$ in diameter) follicles and treated with or without EGF and IGFI during maturation culture. Data presented are means of five replicate experiments. No significant differences were detected.

groups at $6 \mathrm{~h}$ of culture (Fig. 3b). A significant increase in MAP kinase activity compared with at $0 \mathrm{~h}$ of culture was observed at $8 \mathrm{~h}$ of culture in the control, IGF-I only and EGF + IGF-I groups, at which point the value in the EGF only group was significantly higher than that in the control group. In the PB16 oocytes, MAP kinase activity remained high in each of the treatment groups without significant differences among the groups.

\section{Discussion}

The results of the present study are: (i) a significant effect of growth factors on the timing of polar body extrusion of bovine oocytes was detected only when the oocytes were derived from small follicles; (ii) supplementation of the maturation medium with EGF accelerated the timing of polar body extrusion of oocytes derived from small follicles compared with that observed with IGF-I supplementation; and (iii) EGF and IGF-I increased $\mathrm{H} 1$ and MAP kinase activities of oocytes derived from small follicles during early maturation culture, and the increasing effect on MAP kinase activity was most pronounced in the EGF treatment group.

Arlotto et al. (1996) reported that as follicle diameter increases, the proportion of larger oocytes obtained from a specific follicular size class increases, and that larger oocytes extrude the first polar body slightly faster than do smaller oocytes under IVM culture supplemented with fetal calf serum and hormones. In the present study, under serumand hormone-free conditions, the mean frequency of PB16 oocytes from small follicles was lower than that from medium or large follicles when growth factors were not present in the maturation medium, but the differences were not significant. Sakaguchi et al. (2000) demonstrated the 
Table 2. Polar body extrusion of bovine oocytes derived from small ( $\leqslant 3 \mathrm{~mm}$ in diameter) follicles cultured with epidermal growth factor (EGF) or insulin-like growth factor I (IGF-I) or both

\begin{tabular}{lcccc}
\hline & \multicolumn{4}{c}{ Treatment* $^{*}$} \\
\cline { 2 - 5 } Polar body extrusion & Control & EGF only & IGF-I only & EGF + IGF-I \\
\hline PB16 & $101(49 \pm 6)^{\mathrm{a}}$ & $142(67 \pm 6)^{\mathrm{b}}$ & $134(63 \pm 5)^{\mathrm{ab}}$ & $138(75 \pm 4)^{\mathrm{b}}$ \\
PB24 & $85(41 \pm 5)^{\mathrm{a}}$ & $46(22 \pm 6)^{\mathrm{b}}$ & $65(30 \pm 6)^{\mathrm{ab}}$ & $37(21 \pm 4)^{\mathrm{b}}$ \\
No polar body & $21(10 \pm 1)^{\mathrm{a}}$ & $24(11 \pm 1)^{\mathrm{a}}$ & $17(7 \pm 2)^{\mathrm{ab}}$ & $8(4 \pm 1)^{\mathrm{b}}$ \\
Total & 207 & 212 & 216 & 183 \\
\hline
\end{tabular}

*Values are number of oocytes (mean $\% \pm$ SE of five replicate experiments).

PB16 and PB24: oocytes that have extruded the first polar body by 16 or $24 \mathrm{~h}$ after the initiation of culture, respectively.

No polar body: oocytes that have not extruded their first polar body by $24 \mathrm{~h}$ after initiation of culture.

abValues in the same row with different superscripts are significantly different $(P<0.05)$.

accelerating effect of growth factors on the progress of meiosis in bovine oocytes as indicated by polar body extrusion using pooled oocytes from small and medium (1-6 mm in diameter) follicles. The results of the present study using oocytes from size-classified follicles demonstrate clearly that growth factors (EGF + IGF-I) accelerate the meiotic progress of oocytes enclosed by cumulus cells derived from small ( $\leqslant 3 \mathrm{~mm}$ in diameter) follicles only.

Lonergan et al. (1994) reported a clear relationship between follicle size and oocyte quality in terms of oocyte morphology after recovery and blastocyst yield after in vitro fertilization (IVF). Pavlok et al. (1992) demonstrated that oocytes from follicles $1-2 \mathrm{~mm}$ in diameter have a significantly lower competence to undergo IVM and IVF than do those from follicles 3-8 $\mathrm{mm}$ in diameter. Arlotto et al. (1996) also showed that oocytes from small $(\leqslant 3 \mathrm{~mm}$ in diameter) follicles yielded fewer blastocysts than did those from larger $(>3 \mathrm{~mm}$ in diameter) follicles. Together with the results of the present study, which showed that only small follicle-derived oocytes are responsive to growth factors, these findings indicate that the lower developmental competence of oocytes from small follicles might be one explanation for the results of a previous study in which growth factors (EGF + IGF-I) in protein-free medium accelerated the progression of meiosis in oocytes, but did not improve blastocyst yield after IVF (Sakaguchi et al., 2000).

In pigs (Hsu et al., 1987) and humans (Westergaard et al., 1990), it has been reported that the concentration of EGF in small follicles is higher than that in medium and large follicles. In cattle it has been reported that specific EGF binding values are low in preantral follicles but show a 2.5and 5.0-fold increase in both granulosa cells and the theca interna from antral I $(0.16-0.50 \mathrm{~mm}$ in diameter) and antral II (0.6-3.0 mm in diameter) follicles, respectively (Wandji et al., 1992). In contrast, the concentration of IGF-I (Spicer and Geisert, 1992) and its receptor (Spicer et al., 1994) in small follicles is lower than in medium and large follicles in cattle. These results indicate that EGF plays a more important role during the early antral stages of follicular maturation than does IGF-I. In the present study, a greater acceleration of the meiotic progress of bovine oocytes from small follicles was induced by EGF treatment than by IGF-I treatment compared with the control group. This difference in the ability of individual growth factors to accelerate the meiotic progress of oocytes derived from small follicles might be attributed to the stage-specific mechanisms of action of these growth factors in early follicular maturation.

Under conventional conditions for IVM culture, which is supplemented with fetal calf serum and hormones such as gonadotrophins and steroids, bovine oocytes with cumulus cells undergo GVBD at 6-9 h after the onset of maturation (Sirard et al., 1989). It is widely accepted that MPF plays a pivotal role in driving meiotic resumption (Masui and Markert, 1971; Kishimoto et al., 1984; Sorensen et al., 1985; Nurse, 1990). Similar to other mammalian species, the kinetics of activation of MPF (assessed by $\mathrm{H} 1$ kinase activity) precede or occur simultaneously with GBVD in bovine oocytes (Tatemoto and Terada, 1996; Wu et al., 1997), and MPF phosphorylates many of the proteins involved in nuclear membrane formation, chromatin condensation and microtubule reorganization (Verde et al., 1992). In the present study, H1 kinase activity in oocytes derived from small follicles significantly increased from its baseline value at $6 \mathrm{~h}$ of maturation culture with or without growth factors. At $8 \mathrm{~h}$ of culture, the $\mathrm{H} 1$ kinase activity of oocytes in each treatment group continued to increase and the activity in oocytes treated with EGF or IGF-I or both was significantly higher than that of the control group. The good correlation between the rapid increases in $\mathrm{H} 1$ kinase activity caused by growth factors and the rapid meiotic progress of oocytes indicated by polar body extrusion indicates that acceleration of the meiotic progress of bovine oocytes by EGF and IGF-I might be related to an early activation of $\mathrm{H} 1$ kinase activity at about the time of GVBD.

In maturing bovine oocytes, MAP kinase, another essential kinase in the meiotic resumption of oocytes, is activated at the same time as MPF at about the time of GVBD (Fissore et al., 1996; Motlik et al., 1998). In rat 


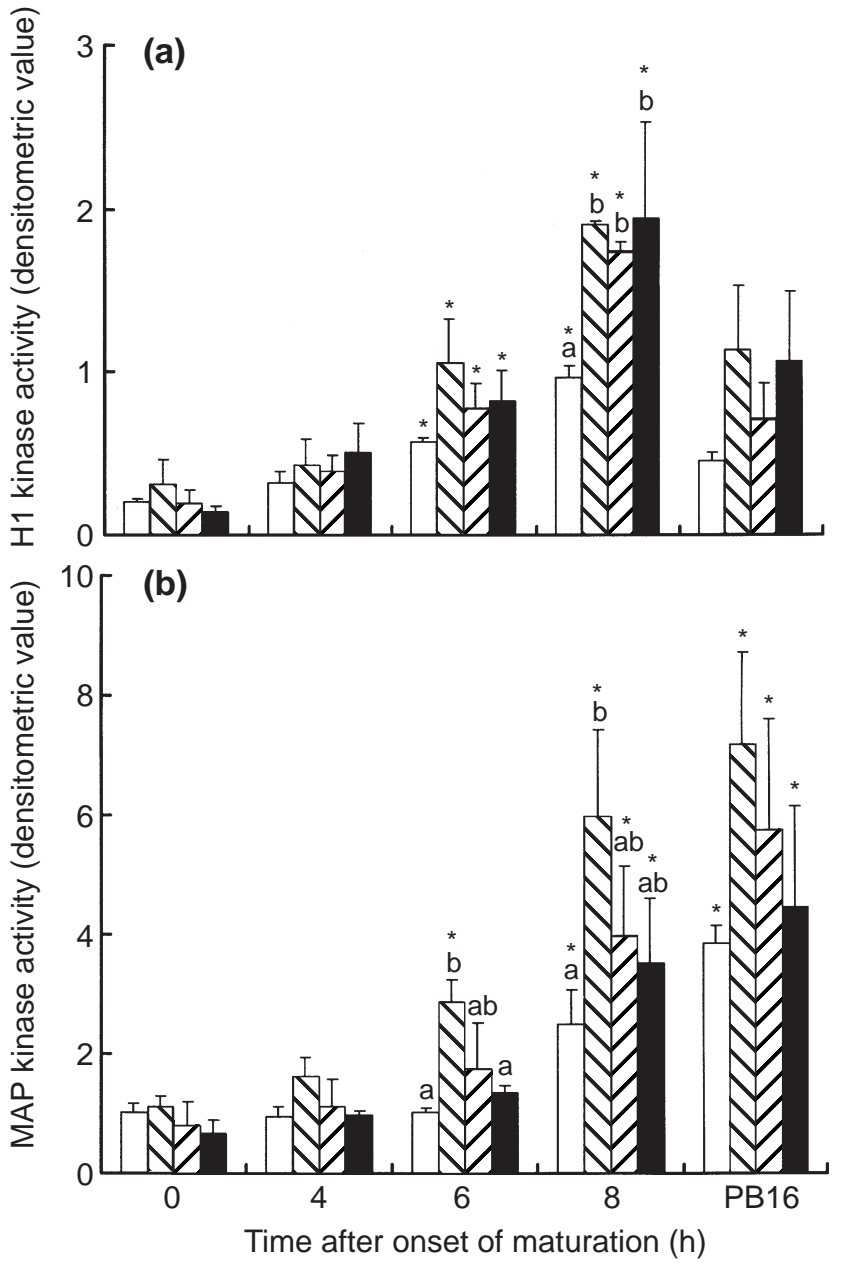

Fig. 3. (a) Histone $\mathrm{H} 1$ kinase and (b) MAP kinase activities in small follicle-derived oocytes treated with growth factors. Cumulusoocyte complexes from small follicles $(\leqslant 3 \mathrm{~mm}$ in diameter) were not treated with growth factors (control; $\square$ ) or were treated with epidermal growth factor (EGF) only ( $\mathbf{Y})$, insulin-like growth factor (IGF-I) only ( $\boldsymbol{Z})$ or with EGF + IGF-I (ם). In each treatment group, oocytes were selected at random for kinase assay at 0, 4, 6 and $8 \mathrm{~h}$ after initiation of maturation culture. Five PB16 (polar body extrusion at $16 \mathrm{~h}$ ) oocytes in each treatment group were also sampled. Data are mean \pm SE ( $n=3$ replicates). The densitometric values of kinase activities were analysed by ANOVA. The means of kinase activity indicated by the densitometric value at each time point were compared with the means at $0 \mathrm{~h}$ (before onset of maturation culture) by paired $t$ test, and the means for the different treatments at the same time point were compared by Fisher's protected least significant difference test. *Significantly different from corresponding value at $0 \mathrm{~h}$ (before onset of maturation, $P<$ 0.05). abValues with different superscripts at the same time point are significantly different $(P<0.05)$.

oocytes, MAP kinase activation alone was insufficient to maintain progression through meiotic maturation and MAP kinase was also implicated in the regulation of microtubule organization (Zernicka-Goetz et al., 1997). These authors also reported that the spindle did not form immediately after MPF activation, but rather after the appearance of MAP kinase activity. In bovine oocytes, the rapid and maximum activation of MAP kinase induced by the product of the proto-oncogene mos results in accelerated resumption of meiosis and GVBD (Fissore et al., 1996). The results of the present study indicate that the MAP kinase activity in oocytes treated with EGF only significantly increased from the baseline value at $6 \mathrm{~h}$ of maturation culture but did not in other treatment groups including the EGF + IGF-I group. From $6 \mathrm{~h}$ to $8 \mathrm{~h}$ of culture, treatment with EGF without IGF-I resulted in higher MAP kinase activity than did the other treatments. This activation effect of EGF on MAP kinase might also be involved with a higher acceleration effect of EGF on meiotic progress. However, the reason why EGF in combination with IGF-I did not have the same ability to increase MAP kinase activity as EGF only is unclear. Further studies are required to clarify the interaction between EGF and IGF-I during maturation of bovine oocytes, including the effects on the kinetics of other cell cycle-regulating kinases such as protein kinases A and C (Rose-Hellekant and Bavister, 1996; Sirard et al., 1998).

The results from analysis of cell cycle stage of fixed oocytes in the present study showed that $55-73 \%$ of PB16 oocytes were at the anaphase I to telophase I stage. This finding, together with early activation of kinase activities in oocytes treated with growth factors, indicates that growth factors accelerate the early stage of oocyte maturation before the formation of the first polar body. Dominko and First (1997) demonstrated that a higher proportion of fertilized oocytes developed to the advanced preimplantation stage when insemination of PB16 oocytes was delayed for $8 \mathrm{~h}$ than when the oocytes were inseminated immediately after polar body extrusion. Although these workers did not analyse the cell cycle stage of polar body oocytes and in the present study the cell cycle progression of the PB16 oocyte after polar body extrusion was not examined, it is possible that delayed insemination of the PB16 oocytes allows the PB16 oocytes at the anaphase I or telophase I stage to form the metaphase II plate, as well as complete cytoplasmic maturation.

Sakaguchi et al. (2000) demonstrated that growth factors do not affect the timing of the polar body extrusion of denuded bovine oocytes in the serum-free culture system and that the acceleration effects of growth factors on the polar body extrusion of bovine oocytes are probably mediated by the enclosing cumulus cells. In rodents, EGF may promote oocyte maturation by disrupting oocyte communication with cumulus cells through the gap junctions (Dekel and Sherizly, 1985), and generation of a positive signal within cumulus cells in response to treatment with growth factors and hormones may act on the oocyte to stimulate GVBD (Downs et al., 1988; Downs, 1989). Prochazka et al. (2000) reported that the disruption of communication or a positive signal might result in rapid increases in $\mathrm{H} 1$ and MAP kinase activities in pig oocytes at the germinal vesicle stage. Thus, it can be speculated that the acceleration effect of growth factors on the meiotic progress of bovine oocytes derived from small follicles is 
exerted through disruption of the communication between cumulus cells and oocytes or by generating the positive signal to the oocyte.

Fair et al. (1995) reported that as follicle size increases to $>3 \mathrm{~mm}$ in bovine follicular oocytes, the growth in oocyte diameter reaches a plateau at about $120 \mu \mathrm{m}$ and oocytes acquire full meiotic competence with transcriptional activity at a diameter of about $110 \mu \mathrm{m}$. These authors also demonstrated that $60 \%$ of oocytes derived from follicles $1-2 \mathrm{~mm}$ in diameter were $<110 \mu \mathrm{m}$ in diameter. Therefore, some of the oocytes from small follicles $(\leqslant 3 \mathrm{~mm}$ in diameter) might be at the final growing phase. The results of the present study indicate that growth factors may act on these oocytes at the final growing phase and accelerate their meiotic progress through enhancing cell cycle-related kinase activities. Examining the changes in diameter of oocytes from follicles of different sizes during maturation culture with or without growth factors will provide additional information to help to explain the effects of growth factors on maturation of bovine oocytes.

In conclusion, EGF and IGF-I act on COCs from small follicles and accelerate the progress of the meiotic cell cycle of oocytes, as indicated by early polar body extrusion. The accelerating ability of EGF may be greater than that of IGF-I, and these two growth factors have an additive promoting effect on the timing of the first polar body extrusion of oocytes derived from small follicles. The accelerating effect may be related to increased $\mathrm{H} 1$ and MAP kinase activities in oocytes mediated by cumulus cells. It is suggested that these possible mechanisms for the action of growth factors on the progress of bovine oocyte maturation must be taken into consideration when these factors are used for improvement of IVM systems.

This work was supported in part by a Grant-in Aid from the Science and Technology Agency (STA) of Japan.

\section{References}

Arlotto T, Schwartz J-L, First NL and Leibfried-Rutledge ML (1996) Aspects of follicle and oocyte stage that affect in vitro maturation and development of bovine oocytes Theriogenology 45 943-956

Barnes FL, Endebrock M, Looney C, Powell R, Westhusin M and Bondioli K (1993) Embryo cloning in cattle: the use of in vitro matured oocytes Journal of Reproduction and Fertility 97 317-320

Bavister BD, Leibfried ML and Lieberman G (1983) Development of preimplantation embryos of the golden hamster in a defined culture medium Biology of Reproduction 28 235-247

Bevers MM, Dieleman SJ, van den Hurk R and Izadyar F (1997) Regulation and modulation of oocyte maturation in the bovine Theriogenology 47 $13-22$

Campbell KHS, Ritchie WA and Wilmut I (1993) Nuclear-cytoplasmic interactions during the first cell cycle of nuclear transfer reconstructed bovine embryos: implications for deoxyribonucleic acid replication and development Biology of Reproduction 49 933-942

Das K, Stout LE, Hensleigh HC, Tagatz GE, Phipps WR and Leung BS (1991) Direct positive effect of epidermal growth factor on the cytoplasmic maturation of mouse and human oocytes Fertility and Sterility $\mathbf{5 5}$ 1000-1004

Dekel N and Sherizly I (1985) Epidermal growth factor induces maturation of rat follicle-enclosed oocytes Endocrinology 116 406-409
Dominko T and First NL (1996) p34cdc2 and p33 CDK2 in regulation of metaphase II arrest in bovine oocytes Theriogenology 45157 (Abstract)

Dominko T and First NL (1997) Timing of meiotic progression in bovine oocytes and its effect on early embryo development Molecular Reproduction and Development 47 456-467

Downs SM (1989) Specificity of epidermal growth factor action on maturation of the murine oocyte and cumulus oophorus in vitro. Biology of Reproduction 41 371-379

Downs SM, Daniel AJ and Eppig JJ (1988) Induction of maturation in cumulus cell-enclosed mouse oocytes by follicle-stimulating hormone and epidermal growth factor: evidence for a positive stimulus of somatic cell origin Journal of Experimental Zoology 245 86-96

Fair T, Hyttel P and Greve T (1995) Bovine oocyte diameter in relation to maturational competence and transcriptional activity Molecular Reproduction and Development 42 437-442

Fissore RA, He CL and Vande Woude GF (1996) Potential role of mitogenactivated protein kinase during meiosis resumption in bovine oocytes Biology of Reproduction 55 1261-1270

Greenwald GS and Roy SK (1994) Follicular development and its control. In The Physiology of Reproduction pp 629-724 Eds E Knobil and JD Neill. Raven Press, New York

Hsu C-J, Holmes SD and Hammond JM (1987) Ovarian epidermal growth factor-like activity. Concentrations in porcine follicular fluid during follicular enlargement Biochemical and Biophysical Research Communications $147242-247$

Hyttel P, Assey RJ, Viuff D and Grondahl C (1993) Transcriptional regulation of oocyte development, fertilization and initial embryonic development in cattle Reproduction in Domestic Animals 28 154-156

Kalab P, Kubiak JZ, Verlhac M-H, Colledge WH and Maro B (1996) Activation of p90rsk during meiotic maturation and first mitosis in mouse oocytes and eggs: MAP kinase-independent and -dependent activation Development 122 1957-1964

Kishimoto T, Yamazaki K, Kata Y, Koide SS and Kanatani H (1984) Induction of starfish oocyte maturation by maturation-promoting factor of mouse and surf clam oocytes Journal of Experimental Zoology 231 293-295

Kubota C and Yang X (1998) Cytoplasmic incompetence results in poor development of bovine oocytes derived from small follicles Theriogenology 49183 (Abstract)

Lohka MJ, Hayes MK and Maller JL (1988) Purification of maturationpromoting factor, an intracellular regulator of early mitotic events Proceedings National Academy of Sciences USA 85 3009-3013

Lonergan P, Monaghan P, Rizos D, Boland MP and Gordon I (1994) Effect of follicle size on bovine oocyte quality and developmental competence following maturation, fertilization, and culture in vitro. Molecular Reproduction and Development 37 48-53

Lonergan P, Carolan C, Van Langendockt A, Donnay I, Khatir H and Mermillod P (1996) Role of epidermal growth factor in bovine oocyte maturation and preimplantation embryo development in vitro. Biology of Reproduction 54 1420-1429

Lorenzo PL, Illera MJ, Illera JC and Illera M (1994) Enhancement of cumulus expansion and nuclear maturation during bovine oocyte maturation in vitro by the addition of epidermal growth factor and insulin-like growth factor I Journal of Reproduction and Fertility 101 697-701

Masui Y and Markert CL (1971) Cytoplasmic control of nuclear behavior during meiotic maturation of frog oocytes Journal of Experimental Zoology 177 129-146

Mordret G (1993) MAP kinase kinase: a node connecting multiple pathways Biology of the Cell 79 193-207

Motlik J, Pavlok A, Kubelka M, Kalous J and Kalab P (1998) Interplay between cdc2 kinase and MAP kinase pathway during maturation of mammalian oocytes Theriogenology 49 461-469

Nurse P (1990) Universal control mechanism regulating onset of M-phase Nature 344 503-507

Pavlok A, Lucas-Hahn A and Niemann H (1992) Fertilization and developmental competence of bovine oocytes derived from different categories of antral follicles Molecular Reproduction and Development 31 63-67

Prochazka R, Srsen V, Nagyova E, Miyano T and Flechon JE (2000) Developmental regulation of effect of epidermal growth factor on porcine 
oocyte-cumulus cell complexes: nuclear maturation, expansion, and Factin remodelling Molecular Reproduction and Development 56 63-73

Rose-Hellekant TA and Bavister BD (1996) Roles of protein kinase A and $\mathrm{C}$ in spontaneous maturation and in forskolin or 3-isobutyl1-1methylxanthine maintained meiotic arrest of bovine oocytes Molecular Reproduction and Development 44 241-249

Sakaguchi M, Dominko T, Leibfried-Rutledge ML, Nagai T and First NL (2000) A combination of EGF and IGF-I accelerates the progression of meiosis in bovine follicular oocytes and fetal calf serum neutralizes the acceleration effect Theriogenology 54 1327-1342

SAS (1989) SAS/STAT User's Guide Statistical Analysis System Institute, Inc., Cary

Sirard MA, Florman HM, Leibfried-Rutledge ML, Barnes FL, Sims ML and First NL (1989) Timing of nuclear progression and protein synthesis necessary for meiotic maturation of bovine oocytes Biology of Reproduction 40 1257-1263

Sirard M-A, Richard F and Mayes M (1998) Controlling meiotic resumption in bovine oocytes: a review Theriogenology 49 483-497

Sorensen RA, Cyert MS and Pederson RA (1985) Active maturationpromoting factor is present in mature mouse oocytes Journal of Cell Biology $1001637-1640$

Spicer LJ and Geisert RD (1992) Concentrations of insulin-like growth factor-I, estradiol and progesterone in follicular fluid of ovarian follicles during early pregnancy in cattle Theriogenology 37 749-760

Spicer LJ, Alpizar E and Vernon RK (1994) Insulin-like growth factor-I receptors in ovarian granulosa cells: effect of follicle size and hormones Molecular and Cellular Endocrinology 102 69-76

Sun QY, Breitbart H and Schatten H (1999) Role of the MAPK cascades in mammalian germ cells Reproduction, Fertility and Development 11 $443-450$
Tan SJ and Lu H (1990) Effects of different oestrous stages of ovaries and sizes of follicles on generation of bovine embryos in vitro. Theriogenology 33335 (Abstract)

Tatemoto $\mathbf{H}$ and Terada T (1996) Activation of p34cdc2 kinase around the meiotic resumption in bovine oocytes cultured in vitro. Theriogenology 45 427-437

Verde F, Dogterom M, Stelzer E, Karsenti E and Leiber S (1992) Control of microtubule dynamics and length by cyclin A-dependent and cyclin Bdependent kinases in Xenopus eggs extract Journal of Cell Biology 118 1097-1108

Wandji S-A, Pelletier G and Sirard M-A (1992) Ontogeny and cellular localization of ${ }^{125} \mathrm{I}$-labeled basic fibroblast growth factor and ${ }^{125}$ I-labeled epidermal growth factor binding sites in ovaries from bovine fetuses and neonatal calves Biology of Reproduction 47 807-813

Westergaard LG, Andersen CY and Byskov AG (1990) Epidermal growth factor in small antral ovarian follicles of pregnant women Journal of Endocrinology 127 363-367

Wu B, Ignotz G, Currie WB and Yang X (1997) Dynamics of maturationpromoting factor and its constituent proteins during in vitro maturation of bovine oocytes Biology of Reproduction 56 253-259

Zernicka-Goetz M, Verlhac MH, Geraud G and Kubiak JZ (1997) Protein phosphatases control MAP kinase activation and microtubule organization during rat oocyte maturation European Journal of Cell Biology 72 30-38

Received 4 June 2001

First decision 21 August 2001.

Accepted 17 September 2001. 